\title{
Novel Flow Field with Superhydrophobic Gas Channels Prepared by One-step Solvent-induced Crystallization for Micro Direct Methanol Fuel Cell
}

\author{
Junsheng Liang $\cdot$ Kuanyao Liu $\cdot$ Shouzuo Li $\cdot$ Dazhi Wang $\cdot$ Tongqun Ren $\cdot$ Xiaoying Xu $\cdot$ Ying Luo
}

Published online: 13 February 2015

(c) The Author(s) 2015. This article is published with open access at Springerlink.com

\begin{abstract}
The $\mathrm{CO}_{2}$-induced capillary blocking in anode flow field is one of the key adverse factors to reduce the performance of a micro-direct methanol fuel cell ( $\mu \mathrm{DMFC})$. In order to solve this problem, new polycarbonate (PC) flow field plates with nested arrangement of hydrophilic fuel channels and superhydrophobic gas channels were designed, fabricated, and tested in this work. The gas channels were treated with solvent-induced crystallization using acetone solution. The superhydrophobicity with $160^{\circ}$ water contact angle and $2^{\circ}$ tilting angle was obtained on the PC substrates. A dummy cell using hydrogen peroxide decomposition reaction and a test loop were separately set up to evaluate the flow fields' performance. It was found that a $37 \%$ pressure drop decrease can be obtained in the new serpentine flow field compared with that of the conventional one. The benefit of the new flow field to remove gas bubbles was also confirmed by an in situ visualization study on the dummy cell. Results show that the auxiliary superhydrophobic gas channels can speed up the discharge of the gas bubbles from the flow field, which will in turn improve the $\mu$ DMFC performance.
\end{abstract}

Keywords Fuel cell $\cdot$ Flow field $\cdot$ Superhydrophobic $\cdot$ Solvent-induced crystallization

\section{Introduction}

Direct methanol fuel cell (DMFC) has been considered as a promising power source candidate due to its advantages such as high energy efficiency, environmental friendliness, room-temperature operation, facile construction, instantaneous refueling, and low or zero noise. Therefore, it has attracted increasing research interests in recent years [1-3].

Gas-liquid management is one of the key factors that impact on the micro-direct methanol fuel cell ( $\mu \mathrm{DMFC})$

J. Liang $(\bowtie) \cdot$ K. Liu $\cdot$ S. Li $~$ T. Ren $\cdot$ X. Xu · Y. Luo

Key Laboratory for Micro/Nano Technology and System of Liaoning Province, Dalian University of Technology,

Dalian 116023, Liaoning, People's Republic of China

e-mail: jsliang@dlut.edu.cn

D. Wang ( $($ )

Key Laboratory for Precision and Non-traditional Machining Technology of Ministry of Education, Dalian University of

Technology, Dalian 116023, Liaoning,

People's Republic of China

e-mail: d.wang@dlut.edu.cn performance. In a liquid-feed $\mu \mathrm{DMFC}$, the byproduct gas bubbles may accumulate in the anode channels, block the transportation of the reactants, and lead to performance deterioration of the fuel cell.

A common method for analyzing gas bubbles in $\mu \mathrm{DMFC}$ is by performing visualization studies to a transparent flow field that provides optical access. Yang et al. observed channel-filling slugs and found that higher flow rates of methanol solution can reduce the average length and number of gas slugs [4]. Liao and coauthors found that the growth and coalescence of $\mathrm{CO}_{2}$ gas bubbles may lead to gas slugs blocking both in flow field channels and the porous diffusion layer [5]. A similar experiment was also conducted by Wong et al. They reported that a smaller flow channel would cause the cell decline in performance because of transient capillary blocking [6].

The appearance and evolution of $\mathrm{CO}_{2}$ bubbles can be quantitatively investigated using micro particle-imagevelocimetry $(\mu \mathrm{PIV})$ technique, as have been reported by Burgmann and coworkers [7, 8]. They found that the cell performance decay is closely related to the formation 
cycles of bubble slugs. An alternative method presented by Numaguchi and co-workers characterized the influence of the $\mathrm{CO}_{2}$ bubbles in anode flow field by detecting the pressure drop along the channels [9]. Results show that the pressure drop may become unstable with a larger periodic fluctuation when current density of the cell is increased. As a result, the periodic accumulation and excretion of the $\mathrm{CO}_{2}$ bubbles in the flow fields were observed, and the periodic fluctuation of the cell voltage will accordingly occur during this process. Buie et al. [10] and Yang et al. [11] further demonstrated the importance of capillary forces by determining the anode pressure drop in a liquid-feed DMFC. Moreover, a Lattice-Boltzmann model was adopted by Zhang and coauthors to investigate the corner effect [12] and hydrophilicity effect [13] on the two-component flow in $\mu \mathrm{DMFC}$.

However, the above-mentioned investigations on gas management that performed in working DMFCs were still limited by the local differences of methanol concentration in the flow field, Ohmic losses in the laterally conducting mesh, and partially visual occlusion on the two-phase flow when using opaque current collectors [14]. On the other hand, the formation, growth, and flow of the gas bubbles may also be disturbed by the temperature fluctuations due to the continuing electrochemical reaction in a running cell. These factors will lead to a certain degree of uncertainty on the bubbles' behavior. In order to deal with this problem, gas management experiments using dummy cells which introduce gas bubbles into the DMFC flow field by chemical gassing reaction in aqueous solution were developed. A method for investigation of two-phase flow in liquid-feed DMFCs using aqueous hydrogen peroxide $\left(\mathrm{H}_{2} \mathrm{O}_{2}\right)$ solution was proposed for the first time by Bewer et al. [14]. This method is based on the decomposition of $\mathrm{H}_{2} \mathrm{O}_{2}$ solution to oxygen and water in aqueous media at the presence of catalyst, which allows for the simulation of the flow distribution in DMFC by perspex-made, low-cost dummy cells and ensures a complete visibility of the flow. The similar gas management studies on DMFCs by mixing aqueous solution of sodium bicarbonate $\left(\mathrm{NaHCO}_{3}\right)$ and weak sulfuric acid $\left(\mathrm{H}_{2} \mathrm{SO}_{4}\right)$ in the DMFC anode flow field were also reported by Meng et al. [15] and Chuang et al. [16]. These works provide important foundation for the studies on "pure" gas behaviors in the DMFC flow fields.

Furthermore, many efforts have also recently been made to mitigate the adverse effects of the gas block in order to improve the $\mu \mathrm{DMFC}$ performance. Lundin et al. reduced $\mathrm{CO}_{2}$ formation at the DMFC anode by chemically enhanced its solubility [17]. The non-equipotent serpentine flow field was proposed by $\mathrm{Li}$ et al., and results showed that the new flow fields could reduce inlet-to-outlet pressure drops and improve the cell performance significantly [18]. Hutzenlaub et al. studied the effects of wettability on both channel walls and diffusion layers in $\mu$ DMFC anode. They concluded that the hydrophilic flow channel can lead to a minimum pressure drop along the channel, and the bubbles will show virtually no pinning inside the channel [19]. However, although these methods have proven effective for reducing the bubble clogging in DMFC flow fields, the two-phase hybrid delivery in a same channel will still inevitably lead to mutual restraint and interference of different components. Hence, there is an urgent need for new flow field designs that can render effective separation of the fuel and gas bubbles.

In this work, a new flow field on transparent polycarbonate (PC) substrate with nested arrangement of hydrophilic fuel channel and superhydrophobic gas channel was presented. The liquid fuel and gaseous byproduct can be separated in situ and delivered in hydrophilic and superhydrophobic channels, respectively. The gas channels were treated with acetone-induced crystallization to obtained superhydrophobic surface, which can selectively enhance the exhaust of gas-phase byproduct from the flow field. A dummy cell that can simulate the formation, growth, and transportation of the gas bubbles in the $\mu \mathrm{DMFC}$ anode flow field by using $\mathrm{H}_{2} \mathrm{O}_{2}$ decomposition reaction was prepared. A test loop was set up to evaluate the performance of the different flow fields, which can be explained by the pressure drop as well as the gas distribution along the fuel channel. The flow fields with and without superhydrophobic gas channels were comparatively studied to determine their different capabilities for mitigating gas slugs blocking.

\section{Experimental Details}

\subsection{Superhydrophobic PC Surface}

The PC plates $(20 \times 20 \times 1.2 \mathrm{~mm})$ were used as the substrates in this study. The PC substrates were rinsed with deionized water and subsequently blown dry with nitrogen. The sample surfaces were immersed in acetone for $5 \mathrm{~min}$, and volatilized naturally. The PC surface morphology was measured by scanning electron microscope (SEM, JEOL JSM-6360LV, Japan). Water contact angle (WCA) on the produced surfaces was obtained with a drop shape analysis system (DSA100, Kruss, Germany) using $5 \mu \mathrm{L}$ sessile drops of water.

\subsection{Flow Field Design and Fabrication}

In order to easily observe the two-phase flow behavior in anode, the PC plates with good transparency were employed as the anode flow field substrates. The flow field parameters are listed in Table 1. An open ratio of $48.9 \%$ for channels on the flow field was adopted. This open ratio 
Table 1 The flow field parameters

\begin{tabular}{ll}
\hline Parameters & Flow field \\
\hline Liquid channel width (mm) & 0.8 \\
Gas channel width (mm) & 0.8 \\
Rib width (mm) & 1.0 \\
Liquid channel depth (mm) & 0.6 \\
Gas channel depth (mm) & 0.4 \\
Liquid channel length $(\mathrm{mm})$ & 39 \\
Active area (mm $\left.{ }^{2}\right)$ & $12 \times 13.4$ \\
Opening ratio (\%) & 48.9 \\
Hydraulic equivalent diameter $(\mathrm{mm})$ & 0.69 \\
\hline
\end{tabular}
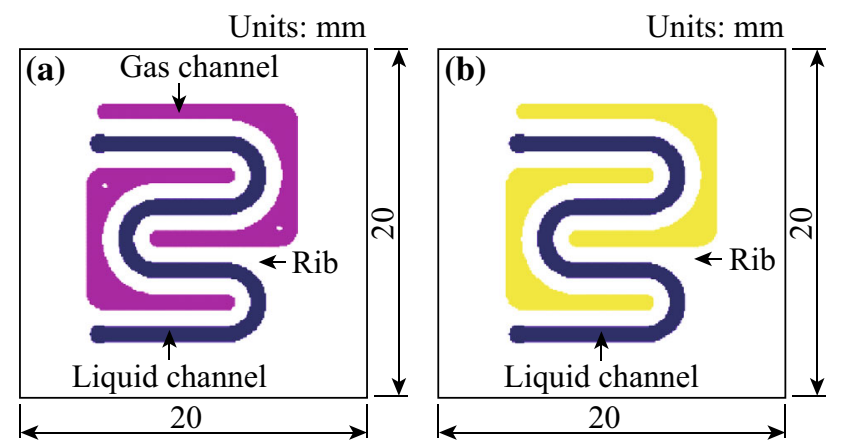

Fig. 1 New flow field a with superhydrophobic gas channels, b without gas channels. (Color figure online)

of close to $50 \%$ can lead to the best cell performance both at moderate and high flow rates of the methanol solution, as has been proved by Yang et al. [20]. Figure 1a shows the new pattern of the flow field, which includes hydrophilic microchannel for liquid transportation, superhydrophobic microchannels for gas exhaust, and ribs for separating the two kinds of channels. The channels were fabricated on the PC substrate with a carving machine. Then the whole flow field plate was covered with thermal adhesive tape (3M8915, 3 M Company, USA), and the tape above gas channels was selectively removed so that acetone could only flow into the gas channels and make it superhydrophobic by solvent-induced crystallization (SIC) treatment. As a comparison, another flow field plate with the same channels pattern but without superhydrophobic treatment in corresponding part of the gas channels in Fig. 1a was also prepared, as can be seen in Fig. $1 \mathrm{~b}$.

\subsection{Test Loop Set-up}

Figure 2 gives the schematic of the test loop set-up. A high accuracy syringe pump was used to transport $\mathrm{H}_{2} \mathrm{O}_{2}$ solution to the dummy cell. Herein, the $\mathrm{H}_{2} \mathrm{O}_{2}$ solution was used to produce $\mathrm{O}_{2}$ gas bubbles in a catalytic reaction with manganese dioxide $\left(\mathrm{MnO}_{2}\right)$ catalyst, and the behavior of $\mathrm{CO}_{2}$

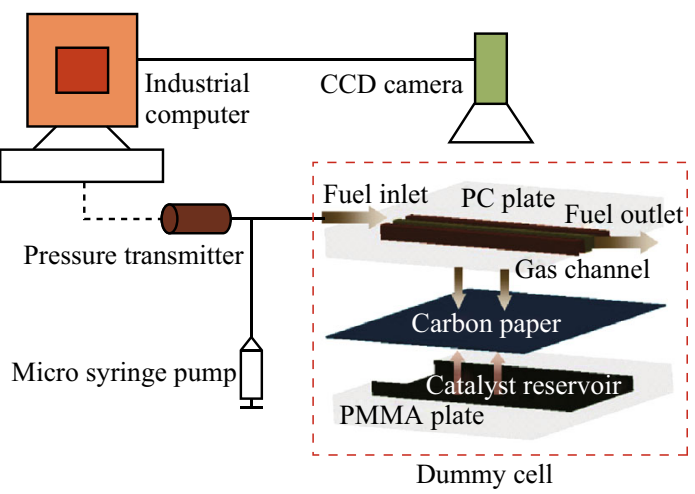

Fig. 2 Schematic of the dummy cell and the test loop set-up. (Color figure online)

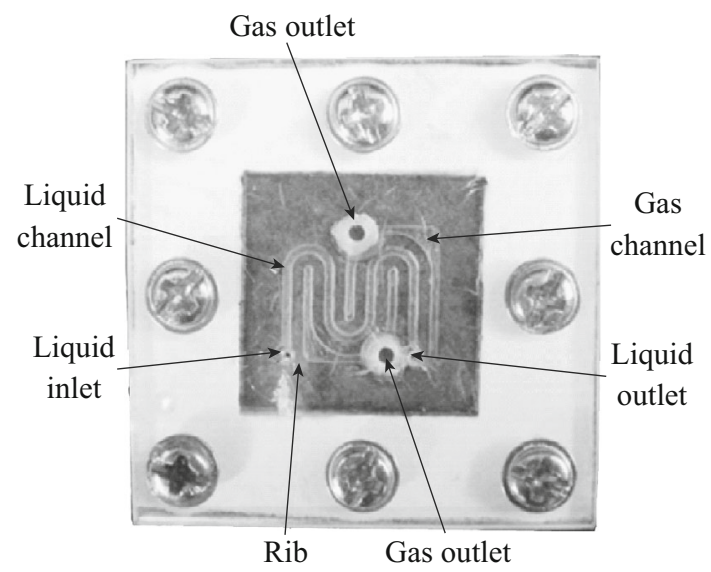

Fig. 3 The dummy cell after assembly

bubbles can be simulated by using $\mathrm{O}_{2}$ bubbles which have the same moles number. The inlet-to-outlet pressure drop was monitored with a pressure transmitter. The digital camera takes 25 frames per second of the two-phase flow in the channels. The industrial computer was adopted to record the flow images from the camera and the pressure drop data from the pressure transmitter.

Figure 2 also shows the principle of the two-phase flow investigations in the dummy cell. The cell consist of catalyst reservoir, carbon paper (as the porous diffusion layer), and new flow field plate. The catalyst reservoir, with a dimension of $15 \times 15 \times 0.8 \mathrm{~mm}$, was engraved on a 2-mm-thick polymethyl methacrylate (PMMA) substrate. The $\mathrm{MnO}_{2}$ (catalyst) loading in the reservoir was $4 \mathrm{mg} \mathrm{cm}^{-2}$. A piece of $20 \times 20 \times 0.28 \mathrm{~mm}$ carbon paper (TGP-H-090, Toray) was immersed in $20 \mathrm{wt} \%$ Polytetrafluoroethylene (PTFE) solution for $5 \mathrm{~min}$ and then dried in an oven at $350{ }^{\circ} \mathrm{C}$ for $30 \mathrm{~min}$ to enhance its hydrophobicity. In the two-phase flow investigation, aqueous $\mathrm{H}_{2} \mathrm{O}_{2}$ solution was used as substitute for the methanol/ $\mathrm{CO}_{2} /$ water mixture. It was fed into the hydrophilic serpentine channel, then diffused into catalyst reservoir through the carbon paper, 

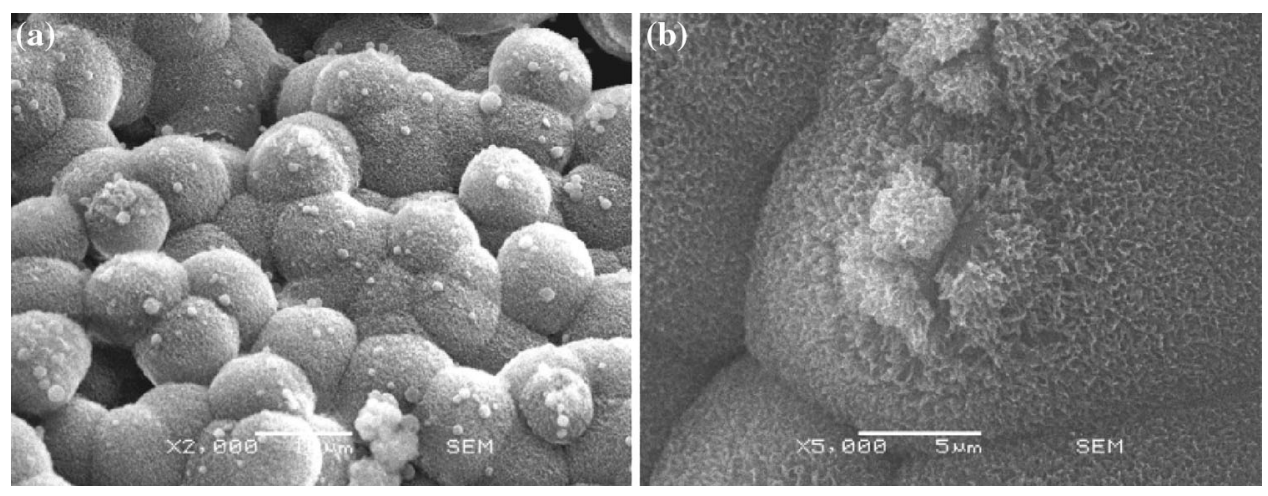

Fig. 4 SEM images of the PC surface treated with SIC technique $\mathbf{a} \times 2,000$ and $\mathbf{b} \times 5,000$

and decomposed into oxygen and water. Most of the oxygen produced in this process was spontaneously released through the superhydrophobic channels due to the wettability gradient of the flow field, and the produced water together with the rest oxygen flew back to the hydrophilic microchannel and was discharged out of the cell by syringe pump. The dummy cell after assembly is shown in Fig. 3. In this experiment, the concentration of the $\mathrm{H}_{2} \mathrm{O}_{2}$ solution was $2 \mathrm{~mol} \mathrm{~L}^{-1}$, which was equivalent to $100 \mathrm{~mA} \mathrm{~cm}{ }^{-2}$ current density in the real fuel cell. The device temperature in the test was set constantly to $25^{\circ} \mathrm{C}$.

\section{Results and Discussion}

\subsection{Morphology of the SIC Surface}

Figure 4 shows the SEM images of PC surface treated with SIC technique. As shown in Fig. 4a, a large number of micrometer-scale spheres with diameter of about $10 \mu \mathrm{m}$ are distributed on the PC surface. The magnified SEM image in Fig. $4 \mathrm{~b}$ shows that the individual micrometer-scale sphere surface consists of many nanometer-scale protrusions, which looks like flower petal. This surface topography of micro-nano hierarchical structure is necessary to produce extreme surface wettability. The forming of this micronano hierarchical structure on PC surface after treatment with acetone can be explained by Hoffman's crystallization theory [21]. When acetone is deposited on the PC surface, the interaction between acetone molecule and PC molecule chain reduces the energy barrier of conformation transition of PC molecule chain, and the polymer chain changes from random linear groups to highly ordered crystallization.

\subsection{Wettability of the SIC Surface}

The PC surface after SIC treatment shows superhydrophobicity, and its WCA was measured as high as $160^{\circ}$, as shown in Fig. 5. Compared to the original PC surface with

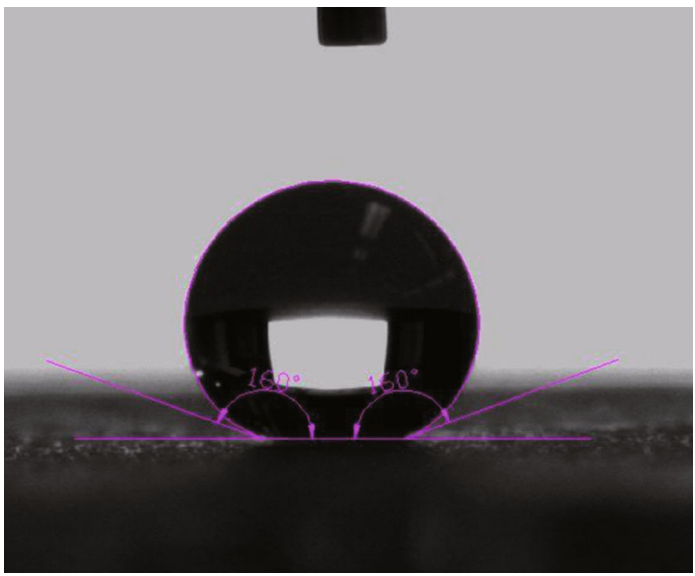

Fig. 5 WCA test on the produced PC surface. (Color figure online)

$82^{\circ}$ WCA [22], the wettability of the treated surface was completely changed. The superhydrophobic properties on the surface can be explained by Cassie-Baxter model [23], $\cos \theta^{*}=f(\cos \theta+1)-1$

where $\theta^{*}$ is the apparent contact angle on a rough surface, $\theta$ is the ideal contact angle on a smooth surface of a sample with the same chemistry, and $f$ is the ratio of wetted surface area to total surface area.

It is easy to estimate from this equation that $f$ is 0.053 , which means that only $5.3 \%$ of the area under the droplet really get in touch with the water droplets. An important parameter to reflect the dynamic wetting behavior is tilting angle, which was also measured as $2^{\circ}$ in the same experiment.

\subsection{Pressure Drop in the Flow Field}

Figure 6 shows the curves of transient pressure drop in flow fields with and without superhydrophobic gas channels at a constant flow rate of $6 \mathrm{~mL} \mathrm{~h}^{-1}$. It can be observed that the time-history curves of both flow fields show 
periodical fluctuation during the test. However, compared to the conventional structured flow field with the average pressure drop of $8.28 \mathrm{kPa}$, the average pressure drop in the new flow field is only about $5.19 \mathrm{kPa}$, which is reduced by $37 \%$. And the average pressure drop amplitude of the flow field, which reflects the stability of the reactants transportation, has decreased by around $67 \%$ (from 1.3 to $0.43 \mathrm{kPa}$ ). It means that the new flow field can effectively retard the bubbles blocking in the fuel channels of the cell.

Effects of $\mathrm{H}_{2} \mathrm{O}_{2}$ flow rates on the pressure drop in flow field were also studied. Figure 7 shows the comparison of the average pressure drop and its amplitudes in flow fields with and without superhydrophobic gas channels. The test was carried out at different $\mathrm{H}_{2} \mathrm{O}_{2}$ flow rates from 6 to $15 \mathrm{~mL} \mathrm{~h}^{-1}$. It can be seen from Fig. 7a that the average pressure drop in flow field with superhydrophobic gas channels is significantly lower than that in flow field without SIC treatment at all flow rates. However, this pressure drop difference tends to reduce with the increase of flow rate. On the other hand, a significant decline of the pressure drop amplitude was

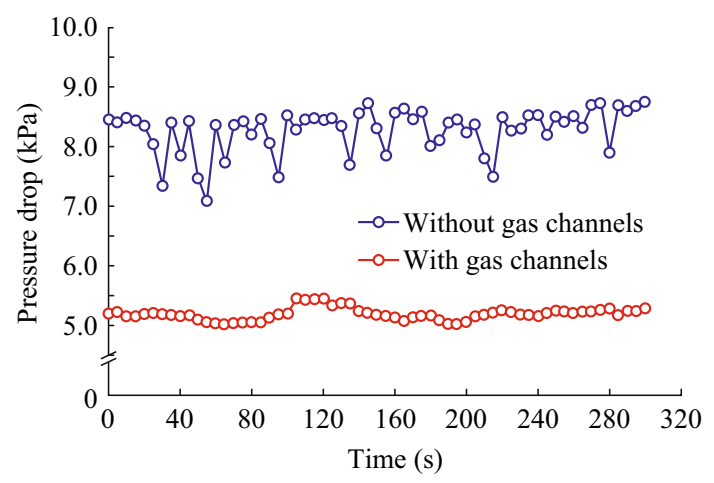

Fig. 6 Transient pressure drop in the flow fields. (Color figure online) observed in the flow field with gas channels compared to that in the conventional one, as shown in Fig. 7b. At the flow rates of 6 and $9 \mathrm{~mL} \mathrm{~h}^{-1}$, the corresponding pressure drop amplitude in the new flow field are only about 31 and $17 \%$ of those in the conventional flow field, respectively. It means that most of the gas can be spontaneously released through the superhydrophobic channels and less fluctuation of the $\mathrm{H}_{2} \mathrm{O}_{2}$ solution transportation was realized. However, when the flow rate was increased to $15 \mathrm{~mL} \mathrm{~h}^{-1}$, the pressure drop amplitude in the new flow field inversely increased, probably because of the liquid that was forced into the superhydrophobic channels, which blocks the gas transportation. Therefore, proper flow rate that does not exceed $9 \mathrm{~mL} \mathrm{~h}^{-1}$ should be adopted in the test.

\subsection{Bubbles Transportation}

An in situ visualization test was introduced in this work to evaluate the gas bubbles clogging in the different flow fields. The experimental condition is analogous to that of the pressure drop measurement. Figure 8 shows the distribution changes of gas bubbles in different flow fields in a time span of $10 \mathrm{~s}$ with the same starting point, and a sequence of images were obtained at an interval of $5 \mathrm{~s}$. As shown in Fig. 8a, when aqueous $\mathrm{H}_{2} \mathrm{O}_{2}$ solution was decomposed in flow field without superhydrophobic channels, the produced $\mathrm{O}_{2}$ will initially form small bubbles, then gradually accumulate and coalesce with each other to generate long gas slugs, and finally block the fuel channel. However, for the flow field with superhydrophobic gas channels, only some small bubbles appear during the reaction, as shown in Fig. 8b. This means that the auxiliary gas channels can speed up the discharge of the gas bubbles, and therefore make the pressure drop and its amplitude in the flow field decline. This visualization result of the bubbles can exactly

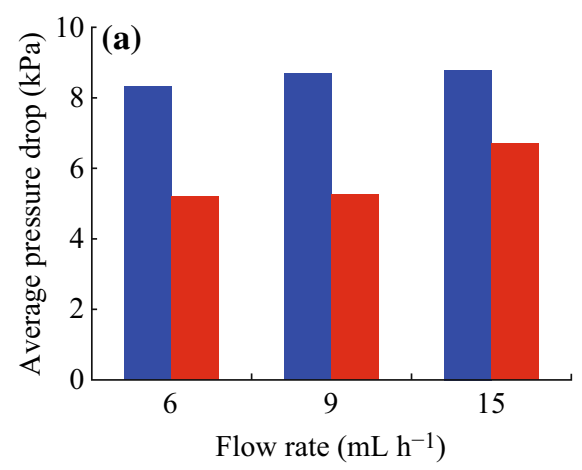

Without gas channels

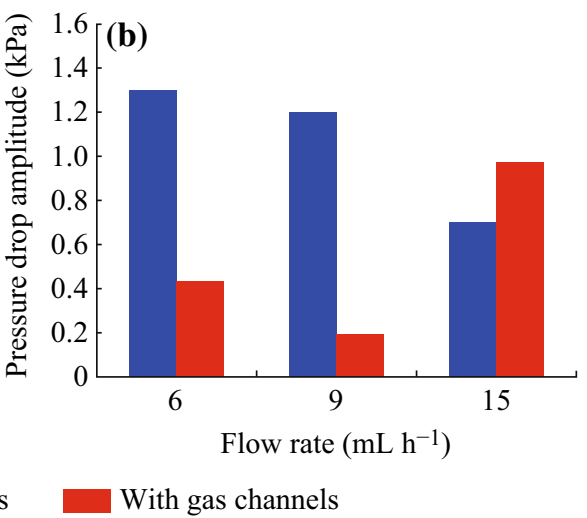

With gas channels

Fig. 7 a Pressure drop comparison in flow fields with and without gas channels: average pressure drop at different flow rates; $\mathbf{b}$ Amplitudes of the pressure drop at different flow rates. (Color figure online) 

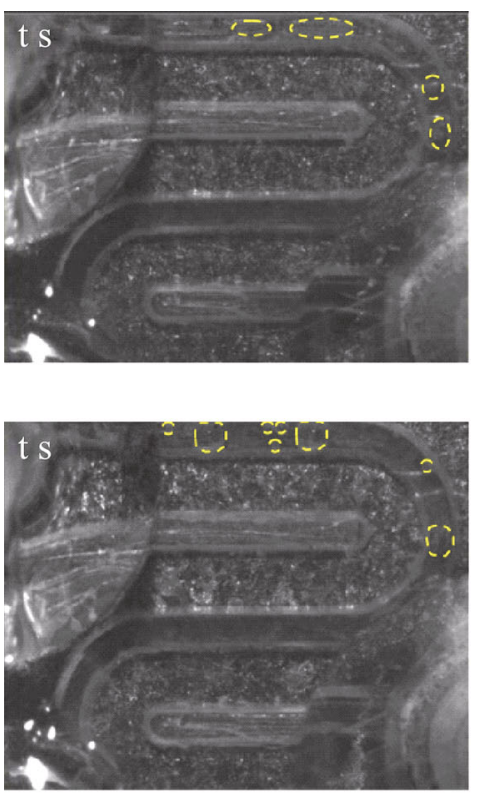

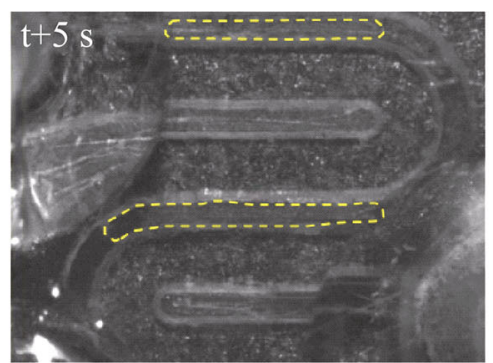

(a)

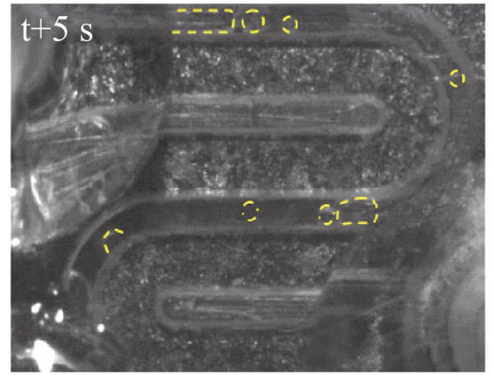

(b)
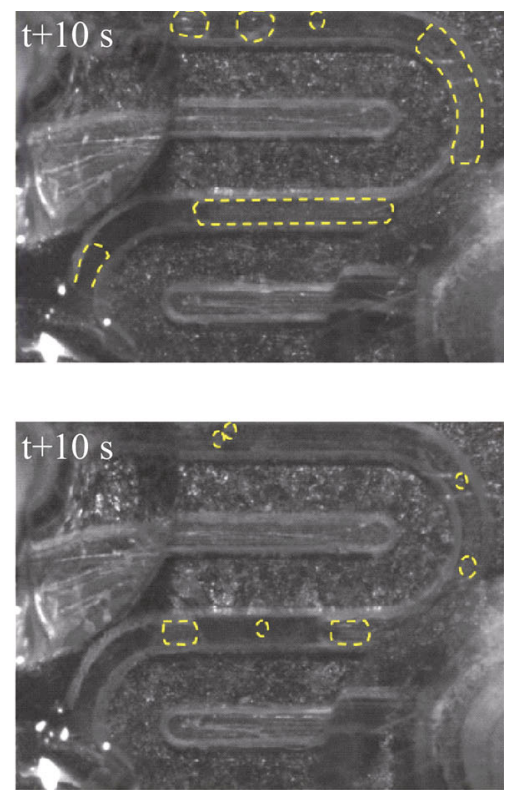

Fig. 8 Gas bubbles distribution in flow field a without gas channels, $\mathbf{b}$ with gas channels. (Color figure online)

provide a reasonable explanation for the pressure drop changes in different flow fields mentioned above.

\section{Conclusions}

In order to enhance the $\mu \mathrm{DMFC}$ performance, the gaseous byproduct produced in the electrochemical reaction needs to be removed effectively. A novel $\mu \mathrm{DMFC}$ anode flow field with superhydrophobic gas channels was presented in this work. The effect of the new flow field design on the two-phase flow was experimentally investigated. A one-step SIC technique was used to prepare superhydrophobic gas channels with $160^{\circ}$ WCA and $2^{\circ}$ tilting angle. Micro-nano hierarchical structure was found in the SEM images of the PC surface after crystallization in acetone. A dummy cell using $\mathrm{H}_{2} \mathrm{O}_{2}$ decomposition reaction and its test loop were separately set up to evaluate the performance of the different flow fields. Results showed that both the pressure drop and its amplitude in the new flow field had a significant decline compared to those in the conventional one. The auxiliary superhydrophobic gas channel can speed up the discharge of the gas bubbles from the flow field, which will in turn improve the $\mu \mathrm{DMFC}$ performance.

Acknowledgments This research is financially supported by the National Natural Science Foundation of China (Nos. 51275076, 51475081).

Open Access This article is distributed under the terms of the Creative Commons Attribution License which permits any use, distribution, and reproduction in any medium, provided the original author(s) and the source are credited.

\section{References}

1. H.X. Zhao, Z. Zheng, J. Li, H.M. Jia, K.W. Wong, Y.D. Zhang, W.M. Lau, Substitute of expensive Pt with improved electro-catalytic performance and higher resistance to $\mathrm{CO}$ poisoning for methanol oxidation: the case of synergistic $\mathrm{Pt}_{-} \mathrm{Co}_{3} \mathrm{O}_{4}$ nanocomposite. Nano-Micro Lett. 5(4), 296-302 (2013). doi:10.1007/BF03353761

2. C. Feng, T. Takeuchi, M.A. Abdelkareem, T. Tsujiguchi, N. Nakagawa, Carbone- $\mathrm{CeO}_{2}$ composite nanofibers as a promising support for a PtRu anode catalyst in a direct methanol fuel cell. J. Power Sources 242, 57-64 (2013). doi:10.1016/j.jpowsour.2013.04.157

3. P. Chen, H.J. Wu, T. Yuan, Z.Q. Zou, H.F. Zhang, J.W. Zheng, H. Yang, Electronspun nanofiber network anode for a passive direct methanol fuel cell. J. Power Sources 255, 70-75 (2014). doi:10.1016/j.jpowsour.2013.12.130

4. H. Yang, T.S. Zhao, Q. Ye, In situ visualization study of $\mathrm{CO}_{2}$ gas bubble behavior in DMFC anode flow fields. J. Power Sources 139(1-2), 79-90 (2005). doi:10.1016/j.jpowsour.2004.05.033

5. Q. Liao, X. Zhu, X.Y. Zheng, Y.D. Ding, Visualization study on the dynamics of $\mathrm{CO}_{2}$ bubbles in anode channels and performance of a DMFC. J. Power Sources 171(2), 644-651 (2007). doi:10. 1016/j.jpowsour.2007.06.257

6. C.W. Wong, T.S. Zhao, Q. Ye, J.G. Liu, Transient capillary blocking in the flow field of a micro-DMFC and its effect on cell performance. J. Electrochem. Soc. 152(8), A1600-A1605 (2005). doi: $10.1149 / 1.1949067$

7. S. Burgmann, M. Blank, J. Wartmann, A. Heinzel, Investigation of the effect of $\mathrm{CO}_{2}$ bubbles and slugs on the performance of a DMFC by means of laser-optical flow measurements. Energy Procedia 28, 88-101 (2012). doi:10.1016/j.egypro.2012.08.043

8. S. Burgmann, M. Blank, O. Panchenko, J. Wartmann, $\mu$ PIV measurements of two-phase flows of an operated direct methanol fuel cell. Exp. Fluids 54, 1513 (2013). doi:10.1007/s00348-013-1513-7

9. T. Numaguchi, S. Hirano, Y. Eguchi, E. Ejiri, Visualization of two-phase flow in DMFC anode channel. ECS Trans. 25(33), 147-154 (2010). doi:10.1149/1.3334802

10. C.R. Buie, J.G. Santiago, Two-phase hydrodynamics in a miniature direct methanol fuel cell. Int. J. Heat Mass Transf. 
52(21-22), 5158-5166 (2009). doi:10.1016/j.ijheatmasstransfer. 2009.05.003

11. H. Yang, T.S. Zhao, Q. Ye, Pressure drop behavior in the anode flow field of liquid feed direct methanol fuel cells. J. Power Sources 142(1-2), 117-124 (2005). doi:10.1016/j.jpowsour.2004. 09.036

12. Z.Y. Yuan, Y.F. Zhang, W.T. Fu, Z.P. Li, X.W. Liu, Investigation of corner effect on micro-scale flow of $\mu$ DMFC. Microelectron. Eng. 111, 96-100 (2013). doi:10.1016/j.mee.2013.02.022

13. Z.Y. Yuan, Y.F. Zhang, W.T. Fu, Z. Wang, X.L. Zhang, X.W. Liu, Hydrophilicity effect on micro-scale flow of $\mu$ DMFC. Microelectron. Eng. 119, 131-136 (2014). doi:10.1016/j.mee.2014. 03.024

14. T. Bewer, T. Beckmann, H. Dohle, J. Mergel, D. Stolten, Novel method for investigation of two-phase flow in liquid feed direct methanol fuel cells using an aqueous $\mathrm{H}_{2} \mathrm{O}_{2}$ solution. J. Power Sources 125(1), 1-9 (2004). doi:10.1016/S0378-7753(03)00824-3

15. D.S. Meng, J. Kim, C.J. Kim, A distributed gas breather for micro direct methanol fuel cell ( $\mu$-DMFC) in Proceedings of Micro Electro Mechanical Systems, MEMS03, Kyoto, Japan (Jan19-23, 2003): IEEE, pp. 534-537 (2003). doi: 10.1109/MEMSYS.2003. 1189804

16. Y.J. Chuang, C.C. Chieng, C. Pan, S.J. Luo, F.G. Tseng, A spontaneous and passive waste-management device (PWMD) for a micro direct methanol fuel cell. J. Micromech. Microeng. 17(5), 915-922 (2007). doi:10.1088/0960-1317/17/5/010
17. M.D. Lundin, M.J. McCready, Reduction of carbon dioxide gas formation at the anode of a direct methanol fuel cell using chemically enhanced solubility. J. Power Sources 172(2), 553-559 (2007). doi:10.1016/j.jpowsour.2007.05.074

18. M.M. Li, J.S. Liang, C. Liu, G.Q. Sun, G. Zhao, Effects of anode flow field design on $\mathrm{CO}_{2}$ bubble behavior in $\mu$ DMFC. Sensors 9(5), 3314-3324 (2009). doi:10.3390/s90503314

19. T. Hutzenlaub, N. Paust, R. Zengerle, C. Ziegler, The effect of wetting properties on bubble dynamics and fuel distribution in the flow field of direct methanol fuel cells. J. Power Sources 196(19), 8048-8056 (2011). doi:10.1016/j.jpowsour.2011.05.070

20. H. Yang, T.S. Zhao, Effect of anode flow field design on the performance of liquid feed direct methanol fuel cells. Electrochim. Acta 50(16-17), 3243-3252 (2005). doi:10.1016/j.elec tacta.2004.11.060

21. J.D. Hoffman, R.L. Miller, Kinetics of crystallization from the melt and chain folding in polyethylene fractions revisited: theory and experiment. Polymer 38(13), 3151-3212 (1997). doi:10. 1016/S0032-3861(97)00071-2

22. I. Saarikoski, M. Suvanto, T.A. Pakkanen, Modification of polycarbonate surface properties by nano-, micro-, and hierarchical micro-nano structuring. Appl. Surf. Sci. 255(22), 9000-9005 (2009). doi:10.1016/j.apsusc.2009.06.073

23. A.B.D. Cassie, S. Baxter, Wettability of porous surfaces. Trans. Faraday Soc. 40, 546-551 (1944). doi:10.1039/tf9444000546 